\title{
Homologous Recombination
}

National Human Genome Research Institute (NHGRI)

\section{Source}

National Human Genome Research Institute (NHGRI). Homologous Recombination.

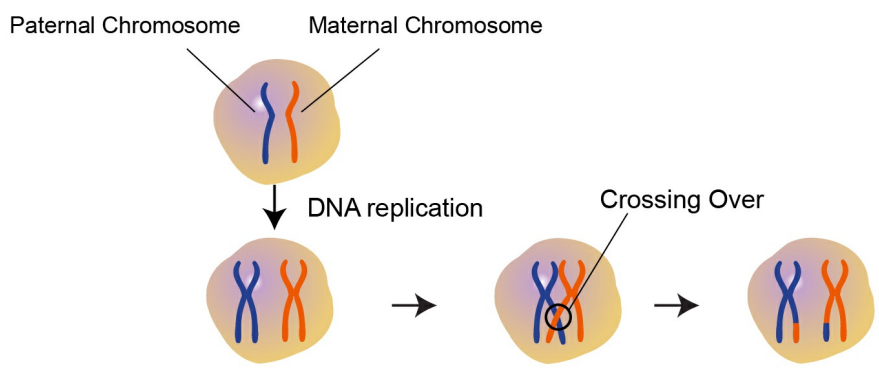

Recombination between 2 homologous chromosomes

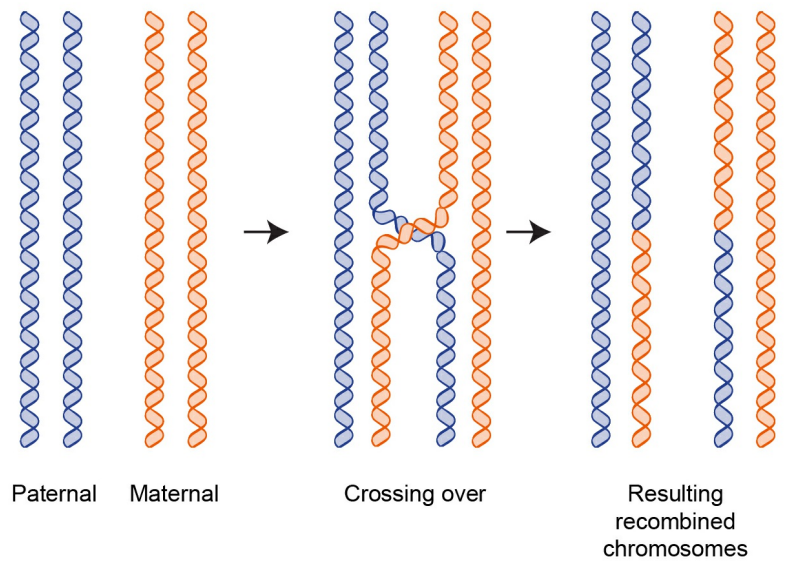

Homologous recombination is a type of genetic recombination that occurs during meiosis (the formation of egg and sperm cells). Paired chromosomes from the male and female parent align so that similar DNA sequences from the paired chromosomes cross over each other. Crossing over results in a shuffling of genetic material and is an important cause of the genetic variation seen among offspring. 